\title{
CARLOS FINLAY, OFTALMÓLOGO Y MICROBIÓLOGO Puerto Príncipe (Cuba), 1833 - La Habana, 1915
}

\section{NOGUERA $J^{1}$}

Carlos Juan Finlay Barrés, inicialmente llamado Juan Carlos, nació en la actual ciudad cubana de Camagüey. En 1855 se graduó como médico en el Jefferson Medical College de Filadelfia (Pennsylvania - EEUU) y en 1856 viajó a París para estudiar neurología y oftalmología. Desde 1857 ejerció la medicina general en La Habana aunque especializado en oftalmología.

Quizá por haber enfermado de cólera entre 1844 y 1846 durante una estancia por estudios en Francia (como consecuencia de esa enfermedad le que-

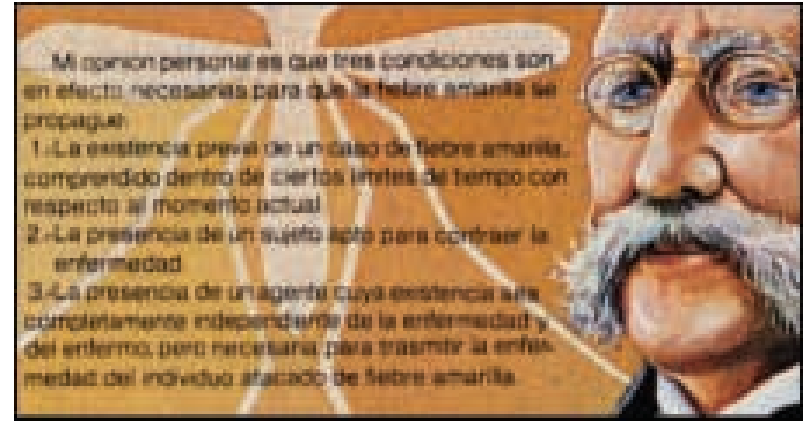

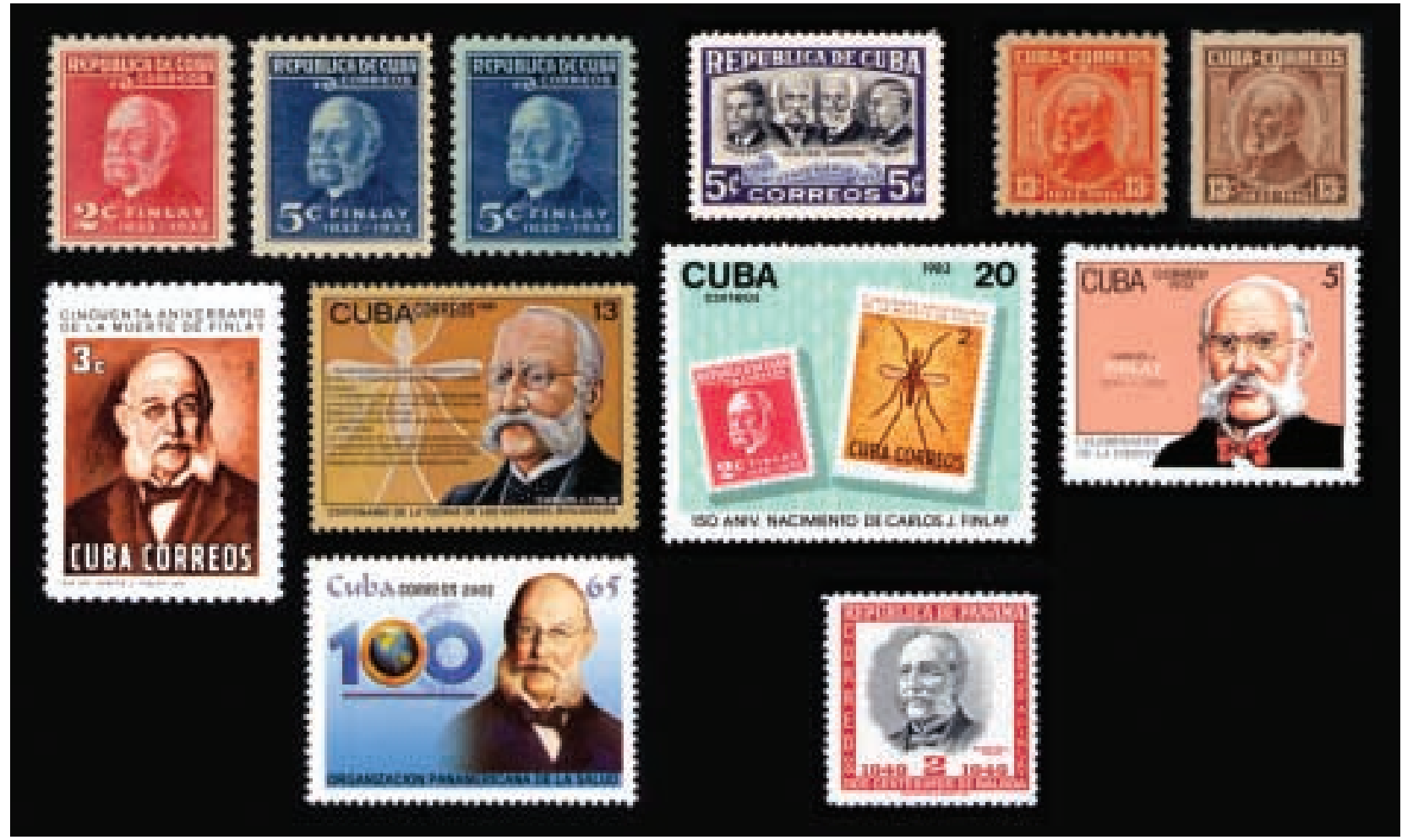

Fig. 1: De arriba abajo y de izquierda a derecha. Cuba: 1934 - Yvert 219/20 (2 sellos y variedad de papel azul); 1952 - Yvert 360 de 358/63 + Aéreo 56/59 + Urgente 14; 1954/56 - Yvert 408 de 402/11; 1964 - Yvert 696B de 696A/96B; 1965 - Yvert 860 de 856/64; 1981 - Yvert 2286; 1983 - Yvert 2473; 1993 - Yvert 3288 de 3287/94 + HB 135; 2002 - Yvert 4059. Panamá 1949 - Yvert 272 de $272+$ Aéreo 110. 
dó un defecto de pronunciación) y movido por la alta incidencia de enfermedades infecciosas que entonces se daban en Cuba, Finlay cambió pronto la oftalmología por la microbiología: en 1860 comenzó a estudiar la fiebre amarilla tras haber trabajado en el cólera y la filariosis. Sus trabajos le llevaron a establecer en 1881 la existencia de un agente transmisor para el contagio de aquella enfermedad: el mosquito Aedes aegypti. Esta teoría no fue confirmada hasta 1900 por una comisión médica estadounidense. En 1905 la fiebre amarilla quedó erradicada de la Habana y en 1909 de toda Cuba.

Sus publicaciones oftalmológicas versaron sobre trastornos visuales por la malaria y la quinina, complicaciones de la atropina, aspectos de la visión binocular, un nuevo método para la extracción de la catarata y la exoftalmía tumoral.

El tres de diciembre, fecha del nacimiento de Finlay, se celebra el Día de la Medicina Americana.

Cuba ha emitido numerosos sellos dedicados a Finlay; un sello más pertenece a los correos panameños. 